\title{
"Perceptions of youth about the integration of natural resource economics through environmental education in schools: a realist social perspective"
}

\begin{tabular}{|c|c|}
\hline AUTHORS & Sikhulile Bonginkosi Msezane \\
\hline ARTICLE INFO & $\begin{array}{l}\text { Sikhulile Bonginkosi Msezane (2017). Perceptions of youth about the integration } \\
\text { of natural resource economics through environmental education in schools: a } \\
\text { realist social perspective. Environmental Economics, 8(3), 70-75. } \\
\text { doi:10.21511/ee.08(3).2017.07 }\end{array}$ \\
\hline DOI & http://dx.doi.org/10.21511/ee.08(3).2017.07 \\
\hline RELEASED ON & Monday, 11 September 2017 \\
\hline RECEIVED ON & Friday, 21 July 2017 \\
\hline ACCEPTED ON & Monday, 21 August 2017 \\
\hline LICENSE & $\begin{array}{l}(c) \text { EY-NG } \\
\text { This work is licensed under a Creative Commons Attribution-NonCommercial } 4.0 \\
\text { International License }\end{array}$ \\
\hline JOURNAL & "Environmental Economics" \\
\hline ISSN PRINT & $1998-6041$ \\
\hline ISSN ONLINE & $1998-605 X$ \\
\hline PUBLISHER & LLC "Consulting Publishing Company "Business Perspectives" \\
\hline FOUNDER & LLC "Consulting Publishing Company "Business Perspectives" \\
\hline
\end{tabular}

$\begin{array}{ccc}0 & 1 & \text { NUMBER OF TABLES } \\ \text { NUMBER OF REFERENCES } & \text { NUMBER OF FIGURES } & \mathbf{0}\end{array}$

(C) The author(s) 2023. This publication is an open access article. 
Sikhulile Bonginkosi Msezane (South Africa)

\title{
Perceptions of youth about the integration of natural resource economics through environmental education in schools: a realist social perspective
}

\begin{abstract}
The purpose of this paper is to delineate the perceptions of grade 12 students about the integration of environmental economics through environmental education into the South African Curriculum and Assessment Policy Statement (CAPS). Margaret Archer's (1995) rralist social theory (RST): the morphogenetic approach provides the metatheoretical framework that informs this study. RST deals with the concepts of structure, culture, agency, pre-existing structures, position-practice systems and mechanisms that have impact on the economic growth and welfare of the society. Data were collected through focus-group interviews with ten students who were purposefully selected from a classroom of 80 students. In addition, a qualitative research approach was used in this study to describe perception of youth about proper utilization of scarce natural resources. The inductive analysis approach was used to interpret raw data sourced from the participants. The results of this paper revealed that even though youth have been taught principles of environmental education which consist of natural resource economics as a cross-curricular topic, some do not appreciate the importance of efficient use of natural resources in the reduction of poverty and welfare of future generation. Further, the youth believe that environmental issues such as land degradation, water and air pollution, and improper solid waste disposal can be alleviated through activities that can be done outside the classroom. However, some participants noted that the local government has to provide financial support for programmes that encourage natural resource sustainability in the schools.
\end{abstract}

Keywords: environmental economics, environmental education, natural resources economics, land degradation, crosscurricular, curriculum, realist social theory, sustainable development.

JEL Classification: Q50, Q53, Q56, I2.

Received on: $21^{\text {st }}$ of July, 2017.

Accepted on: $21^{\text {st }}$ of August, 2017.

\section{Introduction}

Since the dawn of the new millennium there has been a proliferation of policies and political rhetoric worldwide, stressing the importance of equitable and sustainable development without depleting natural resources (Knutsson, 2011). Environmental education (EE) plays a vital role in ensuring that society is knowledgeable on the aspects of sustainable development such as poverty alleviation, economic growth, marginal costs and marginal benefits of preserving natural resources. EE first manifests in the promotion of nature and outdoor study in primary schools and later in the conservation movement (Stevenson, 2007). Importantly, when it comes to taking care of natural resources for future generations, ensuring sustainable usage and maintaining our valued environment, education plays an important role. Significantly, the goals of EE, which also form the background of this study, involve the critical tasks

(C) Sikhulile Bonginkosi Msezane, 2017

Sikhulile Bonginkosi Msezane, Med, Ph.D. Candidate, Lecturer, College of Education, Schools of Educational Studies, Department of ABET and Youth Development, University of South Africa, South Africa.

This is an Open Access article, distributed under the terms of the Creative Commons Attribution-NonCommercial 4.0 International license, which permits re-use, distribution, and reproduction, provided the materials aren't used for commercial purposes and the original work is properly cited. of appraising of environment, formulating moral codes concerning environmental issues, and participating actively in environmental improvement (Stevenson, 2007). Furthermore, EE is concerned not only with social reconstruction to reduce exploitation of the environment, but also with the avoidance of social injustices in the process of that reconstruction. The injustices emanate from monopoly capitalist, who retard socio-economic growth of South African people by using natural resources sparingly for financial gains. According to Andersson (2016), one of the concepts of EE is Education for Sustainable Development (ESD), which is considered to be the key factor for changing attitudes and behavior. ESD is essential to get citizens to accept policies aimed at steering society in a more sustainable and economic direction. Therefore, schools, teachers and other role players can achieve sustainable environmental goals through EE. In fact, the United Nations decade of sustainable development (2005-2014) had the vision that ESD should promote holistic learning of the environment, including issues pertaining to the economic and political perspectives. The 17 goals of sustainable development were adopted prior to this decade. Significantly, United Nations goal four ensures inclusive and quality education for all and promotes lifelong learning, which forms part of the perspective of this investigation. Obtaining a quality 
education is the foundation to improve people's lives and achieve sustainable development (UN, 2015).

On the same note, Andersson (2016) mentions that many are putting their faith in ESD and the teachers teaching it, and that there is space for conducting more studies in this field, to ascertain whether variation in the content and organization of ESD in the teacher education program has different effects on future teachers and how they teach EE. Certainly, this paper addresses the gap between teacher, learner, content and knowledge of EE integration as cross-curricular content in the curriculum based on natural resource economics. This paper investigates the perception of students about the integration of environmental economics in the curriculum. In addition, the study illuminates Margaret Archer's (2003) Realist Social Theory (RST), which is a meta-theoretical framework, which informs and locates the basis of EE in the education sector. This investigation also reveals the contributions of learners in focus group interviews, where the participants were purposefully selected for this research.

Students' (youth) perceptions will indicate whether $\mathrm{EE}$ is adequately afforded the required space in the curriculum and whether teachers' knowledge of EE assists in learners' appreciation and understanding of sustainable development, which is one of the principles of UN Sustainable Development Goals. Successful EE should lead to fundamental changes in the values and norms of citizens in the future. Therefore, knowledge about SD should pervade all levels of education and all learning. Sund (2015) mentions that most studies nowadays focus on the ways in which SD is understood by teachers. In contrast, learners' experience of environmental studies and environmental knowledge acquisition, and understanding of EE concepts such as natural resource economics is still underresearched. There is still doubt about how knowledge about SD is cascaded to learners and whether teachers give learners time to think about environmental issues in the school situation (Knutsson, 2011). Consequently, this paper outlines the varying perceptions of learners about environmental education in the South African curriculum.

Research problem. This paper looks at students' grasp of the concepts of EE, against the background of ideologies which advocate for environmental reform, which require from the students to engage in ideological and critical enquiry (Stevenson, 2007). Students need to be aware of the current situation and be able to deliberate on EE integration in the school curriculum. The voices of students have to be heard, if one wishes to determine whether $\mathrm{EE}$ is addressing their academic needs, as well as the global goals of sustainable development.

This paper is based on the following research questions:

- What is the perception of students about studying EE as cross-curricular content in South African schools?

- What are the pre-existing assumptions of EE integration into the curriculum based on RST (that is, the concepts of structure, culture, agency, position-practice systems, mechanisms, relations and how they are linked to each other in reality)?

Purpose of the paper. The goals of EE, that is, nature study and conservation education, have to be relatively accommodated in the goals and structural organization of schools. Moreover, Stevenson (2007) noted that the critical enquiry and action orientation inherent in EE create a challenging task for schools. This challenge is at the root of the purpose of this paper, which is to delineate the perceptions of grade 12 learners about studying environmental education (EE) in the context of the South African Curriculum and Assessment Policy Statement (CAPS). The paper adopts Margaret Archer's ideas (1995) as proposed in her work Realist social theory (RST): the morphogenetic approach. RST is used to evaluate the pre-existing concepts and views of students about EE in order to find out the scope of $\mathrm{EE}$ integration in the curriculum.

Theoretical framework. As indicated, this paper adopts Archer's (1995) realist social theory (RST) as the meta-theoretical framework that informs and locates the basis of this study. This theory is explanatory and seeks to understand the operations of social programs by evaluating their operational successes and failures for various interest groups functioning in a particular context (De Souza, 2013). According to De Souza (2013), RST methodology is a social theory about individuals in society, focusing on how individuals and society are related and how the interactions between them that might bring about or hinder change in the social context of interest. In this paper the individuals are students who are exposed to a school program of learning. Students interact with society by imparting knowledge of what they have learned in school through EE. Archer reveals that the work on realist social theory has generally directed its efforts to explaining society and its transformation or reproduction. In order to explain and describe the mechanisms of the workings of a society, social realists have adopted certain terminology. These terminologies include "structure", "culture", 
"agency" and "relations". Archer points out that social structure can include structure, culture, agency and relations, which can then all be referred to as "institutional structures". The institutional structures in this paper are schools.

On reference to RST concepts, this paper's context of action refers to the teaching of students in schools where social actions pre-suppose the existence of certain conditions for engaging in those actions. In this paper, institutional structure refers to sets of objects in schools, such as classrooms, teaching and learning materials and practices, which can be human resources such as teachers, administrators and general workers in schools. Archer (1995) reports that culture represents ideas and ideational influences operating between people. Culture both shapes and is shaped by people. This can be done through ideas informing the actions of individuals to achieve a possible outcome. In this paper "culture" involves pedagogy and the behavioral changes of students after being taught EE.

Another concept of RST is "agency", which entails individuals in a society engaging in action or nonaction under the influence of institutional structures and cultural conditions. The agency in this paper are students and teachers who are engaged in and can be influenced by the structural and cultural conditions of the school. Agency is also influenced by the practices designated by the social position held (De Souza, 2013). According to Bhaskar (2008), it is through this interrelationship between society and positioned practices engaged in by individuals, that social structures in society are reproduced or transformed. In this paper, we investigate whether the perceptions of students indicate the reproduction or transformation of social structures after being exposed to EE at school. Relations can be duties, rights, power and responsibilities. In this paper, it is noted that students have relations with the institutional structures based on rights, duties and responsibility.

\section{Methodology}

This paper investigating the perceptions of students about EE integration in the CAPS is based on a qualitative research design. In qualitative research the focus is on educational research in which the researcher collects data based on the views of participants by asking probing questions, and collecting data in the form of words from participants (Creswell, 2008). The research design comprised the sample, instruments employed in the investigation and procedures for data analysis.
1.1. Sample of the investigation. Purposeful sampling was used for choosing the participants. The target group consisted of two classes in one of the schools in the Mkhondo location, in Mpumalanga. The classes were both grade 12 classes and all the students were taught subjects that included EE as cross-curricular content. From these classes ten students were purposefully sampled to take part in the focus group interviews for this paper. The participants were both girls and boys from the ages of 17 to 19 years old.

1.2. Instruments and procedures. Focus groups were utilized to source information from the participants in this research. De Vos et al (2006) indicate that focus-group interviews are a means of understanding how people feel or think about an issue, product or service. After piloting an interview guide with students who were not going to be part of the final data collection, the researcher posed a number of questions and gathered responses from the participants in the group. The participants were asked questions on their perception of $\mathrm{EE}$ integration according to the sequence stipulated in the interview guide. The learners' responses were recorded using mobile phones and a paper notebook. The raw data that were gathered from the focus group interviews was then analyzed.

1.3. Data analysis. The data analysis was aimed at seeking patterns in the raw data that was collected in the focus-group interviews. According to Stake (1995), the analysis of data entails giving meaning to first impressions as well as final compilations. In this paper, inductive data analysis was used in the development of categories of raw data that could be discussed. Therefore, the data interpretation was done after all the analyses have been completed.

\section{Findings}

The major findings of this study based on the RST concepts of institutional structure, culture, agency and relations are as follows:

- Students positively acknowledged the institutional structural orientation in schools and its functions in terms of EE integration in the school.

- Students perceived cultures in schools and their mechanisms to achieve environmental transformation as important.

- Students also revealed considerate views on aspects of culture which are informed by mechanisms related to ideas or propositional formulations about structure, culture, agency and relations.

- Students had difficulties with the structure, which is informed by mechanisms related to roles, practices, resources and processes towards incorporating EE in the school curriculum. 


\section{Discussions}

Sund (2015) believes that visualizing how environmental concepts are integrated into the real world (as a teaching approach) evokes discussions amongst leaners who want to know more about the issues being discussed. Andersson (2016) pointed out that teachers and learners, if they have strong views about sustainable issues, will have an impact on teaching and learning in the school environment.

3.1. Structure. The structural organization of schools in the form of classrooms that has been in existence over almost two centuries has maintained its purpose, which is to enable the practice of correct skills for the accumulation of knowledge by students. The primary role of schools is to transmit cultural knowledge, skills and values. According to Stevenson (2007), schools are faced with the challenge of finding the culture it is to transmit. In this research, it was found that students believe that institutional structures are important in order to accumulate knowledge. Students responded that the role of $\mathrm{EE}$ in the school and society involves sustainable use of natural resources. They also mentioned that EE is taught in different subjects as a cross-curricular component. This declaration by the learners showed that they are aware of the importance of EE in their structure at school level. One participant responded when asked about the role and importance of EE in the school by saying "It keeps us healthy through food, fresh air that we breathe and source of tourist attraction". The participants also revealed insight into the role of EE in advocating programmes in society that aim to prevent the degrading of natural resources.

3.2. Culture. The social and structural purpose of schooling is to present important and basic information to enable the practice of correct skills and to maintain the existing social conditions and relations (Stevenson, 2007). The students revealed ideas about cultural change that are associated with cultural integration. They indicated that the theories, beliefs, values and arguments about sustainable natural resources are embedded in the structure of teaching and learning resources. This supports the culture of sustainable natural development and is confirmed by one of the participants who mentioned that EE is essential to ensure that natural resources are sustained for future generations: "Future generations have to benefit from the very same environment for their livelihood". The students in this study also showed an emergent proposition of culture when they said that: "Posters educating about the importance of environment should be visible at school". This perception of the students encourages some of the initiatives that can be used to educate young citizens through other methods outside traditional classroom activities. It can also be used to support the culture of SD through EE using the school structures.

3.3. Agency. Agency is the main concept of RST in this paper, which encompass mechanisms related to the individual's beliefs and reasons for action and non-action under the influence of institutional structure and cultural conditions. These conditions exist while students interact with the school curriculum and structures. The students' perceptions, as determined in this study, highlight the influence of teachers and pedagogy in the integration of $\mathrm{EE}$ in the curriculum. Hence, the teacher aspect and the student aspect formed the basis of agency as postulated by Archer (1995) in her RST.

The following discussions are based on the categories emanating from the students' perceptions about EE. These are changes in behavior, beliefs, knowledge, skills and values.

3.4. Behavior. Learners understand lessons better when they spend all the time in a classroom engaged in practical activities which are scientifically driven, testing arguments about the relevant topics, solving problems, and reasoning (Deslauriers et al., 2011). In addition, Andersson's (2016) study noted that future teachers with a pre-existing intense moral obligation to contribute to SD, easily influence learners' opinion about the environment. Over the years, research in environmental psychology has produced a lot of literature on how people acquire pro-SD beliefs and norms. On the same note, Andersson (2016) reported that in a phenomenography study by Corney and Reid in 2007, it was revealed that teachers had difficulty in dealing with their own personal values when teaching about environmental concepts. This study also found that teachers in tertiary institutions are not well oriented towards SD, which is one of the major strands in EE (Andersson, 2016). Therefore, proenvironmental behavior has its roots in personal values where behavioral activities are the result of a causal chain that starts with personal value priorities (Andersson, 2016).

Often, during the interviews with the learners, the responses showed contrasting perceptions about EE integration in the curriculum. The perception students have about environmental economics is that it enlightens people about the importance of conserving natural resources. Yet, they were struggling to outline evidence on how natural resources can be protected for future generations and eradication of poverty from overuse of natural resources. Consequently, their behavior could not be entirely changed by EE being incorporated into the curriculum. 
3.5. Beliefs. According to Stern (2000), personal value priorities affect beliefs and the development of personal norms, attitudes and behavior. Such personal values will also enlighten today's young citizens about the fact that our lifestyles must change. Other studies showed that interactive and practical teaching strategies, including reasoning and problem-solving, had a strong effect on students' engagement and knowledge when compared with traditional approaches (Deslauriers et al., 2011). Teachers should create a stronger belief about sustainable issues, because it can be easily cascaded to learners during teaching. The students believed that what they are learning in school pertaining to EE is important and teachers should put more emphasis on the principles of SD. Furthermore, Andersson (2016) is of the opinion that youth should be pushed beyond their limits and that their minds should be engulfed with environmental issues, so that this will lead to a proSD direction of thought and action. The participants noted that the teachers' beliefs about EE principles and values greatly influence the manner in which they teach EE particularly natural resource economics. Participants mentioned, that this would enhance how they would interact with natural resources in future.

3.6. Knowledge, skills and values. Stevenson (2007) mentions that the Tbilisi Declaration of 1978 considers the characteristics of curriculum and pedagogical practices as being important in addressing the goals of EE. These characteristics place the emphasis on students focusing on working individually and collectively towards the resolution of current environmental issues. Also, teaching and learning need to be a co-operative process of inquiry into and action in respect of real environmental issues. This process, according to Stevenson (2007), needs students to actively engage in complex thinking about real problems. Therefore, the development of knowledge, skills and values is not only directed towards action, but emerges in the context of preparing to take action. After being exposed to EE lessons, the participants realised that their knowledge, skills and values with regard to the environment have changed considerably. They also had the view that EE helped them to appreciate nature and see nature as an important aspect in their daily lives. The participants further elaborated that the environmental concepts in subjects such as life sciences and geography did not only improve their natural resource economics skills, but also imparted necessary knowledge for their future aspirations. Therefore, pedagogical planning needs to be adaptable to students' own social constructs and the teacher should be responsive to the students' decisions in relation to both their learning and their economic actions (Stevenson, 2007).

3.7. Interrelations between environmentally significant behavior, beliefs, knowledge, skills and values. Stern (2000) highlighted that the valuebelief-norm model states that values lead to environmental beliefs, which then later lead to personal norms, attitudes and behavior. Stern (2000) pointed out that environmental behavior can be defined by its impact, which is the extent to which it changes the availability of materials or energy from the environment, which alters the structure and dynamics of ecosystems. Certainly, behavior can be altered in the manner that the unacceptable disposal of household waste can corrected, in what Stern (2000) terms as proximal environmental change. Some behaviors are influenced indirectly by shaping the context in which choices are made that directly cause environmental change (Stern, 2000). This is evident in this paper, where the perceptions of students about EE point to the interaction of structure, culture and agency. According to Stern (2000), behaviors that affect policies, commodity prices on world markets, environmental policies and tax policies have a greater indirect environmental impact than behaviors that directly change the environment. Stern (2000) further mentions that environmental impact has largely been a by-product of human ambitions for physical comfort, mobility, relief from labor, enjoyment, power, personal security, technologies and so forth. Therefore, students' perceptions about EE integration in the curriculum had to be grounded in behavioral changes. The participants were aware of difficulty, ambiguity, contradiction, autonomy and uneasiness as characteristics of classroom disorder. Therefore environmental dialogue needed to implement strategies which encouraged continuous, constructive and reflective consideration of the natural challenges facing the environment today.

\section{Conclusion}

The aim of this paper was to delineate the perceptions of youth about the integration of natural resource economics through EE in the South African Curriculum and Assessment Policy Statement (CAPS), guided by the RST. The perceptions of the youth who were interviewed revealed that behavior, beliefs, knowledge, skills and values played an important role in ensuring that $\mathrm{EE}$ is efficiently integrated into the curriculum. The results also indicated that structure, culture and agency, which are the concepts of RST, play an important role in EE integration. The results shed light on the socio-economic transformative effect that $\mathrm{EE}$ has on the lives of the participants. 
However, some participants voiced some concerns about the manner in which teachers impart important knowledge about SD during lessons.

To summarize, this research discovered that participants have good knowledge of the implications of $\mathrm{EE}$ integration and the behavioral changes that follow as a result of being taught aspects of natural resource economics in schools. The participants also noted that EE implementation in schools challenges the conception, organization and transmission of knowledge, which often creates problems for students, as well as teachers based on their economic background. Also, the youth noted that government agencies should provide financial support in programs associated with environmental economics in schools, so that the socio-economic status of the people can be improved through education.

\section{Recommendations}

This research recommends that this type of research can also be carried out with the view of teachers who are engaged with students in the education sector to find out their views into the integration of environmental economics through $\mathrm{EE}$ in schools. Further studies should be done to solicit the extent of environmental economics topics coverage in the examination papers that are given to learners at the end of the year. This paper also recommends that developing countries, such as South Africa, should ensure that education for sustainability initiatives are financially supported in order to reduce natural resources degradation that influences negatively the socio-economic transformation of the society.

\section{References}

1. Andersson, K. (2016). Starting the pluralistic tradition of teaching? Effects of education for sustainable development (ESD) on pre-service teachers' views on teaching about sustainable development. doi: http://dx.doi.org/10.1080/13504622.2016.1174982

2. Archer, M. S. (1995). Realist social theory: the morphogenetic approach. New York: Cambridge University Press. Retrieved from http://lchc.ucsd.edu>xmcamail.2015-02.dir

3. Bhaskar, R. (2008). A realist theory of science. New York: Routledge.

4. Creswell, J. W. (2008). Educational research: planning, conducting and evaluating qualitative and quantitative research. Boston, MA: Pearson International.

5. Deslauriers, L., Schelew, E., Wieman, C. (2011). Improved learning in a large enrolment Physics class. Science, 332(6031), 862-864. doi: http//dx.doi.org/10.1126/science.1201783

6. De Souza, D. (2013). Elaborating the context-mechanism-outcome configuration (CMOc) in realist evaluation: a critical realist perspective. Evaluation, 19(2), 141-154. Retrieved from https://www.researchgate.net/publication (accessed on November 2, 2016).

7. De Vos, A. S., Strydom, H., Fouche, C. B., Delport, C. S. L. (2006). Research at grassroots for the social sciences and human service professions. Pretoria: Van Schaik.

8. Knutsson, B. (2011). Curriculum in the era of global development: historical legacies and contemporal approaches. Retrieved from http//hdl.handle.net/2077/27936

9. Stake, R. E. (1995). The art of case study research. Thousand Oaks, CA: Sage.

10. Stern, P. C. (2000). New environmental theories: towards a coherent theory of environmentally significant behavior. Journal of Social Issues, 56(3), 407-424. Retrieved from http://citeseerx.ist.psv.edu

11. Stevenson, R. B. (2007). Schooling and environmental education: contradictions in purpose and practice. Environmental Education Research, 13(2), 139-153. Retrieved from http://dx.doi.org/10.1080/13504620701295726 (accessed on November 3, 2016).

12. Sund, P. (2015). Experienced ESD schoolteachers' teaching: an issue of complexity. Environmental Education Research, 21(1), 24-44. doi: http://dx.doi.org/10.1080/13504622.2013.862614

13. United Nations (2015). Sustainable Development Goals. Retrieved from www.https:sustainabledevelopment.un.org (accessed on November 15, 2016). 